\title{
Os reveladores da mentira
}

\section{A. Almeida Júnior}

Para constranger testemunhas ou acusados a dizer a verdade, três categorias de processos têm sido praticados:

a) os que enfrentam diretamente o psiquismo conciente, coagindo o declarante, pela violência, a escolher entre o sofrimento "atual", artificialmente infligido, e o sofrimento "futuro", decorrente da revelação da verdade: são os vários tipos de tortura inquisitiva;

b) os que, fazendo adormecer as forças inibitórias do psiquismo superior, facilitam a reprodução, por palavras, do fato que o declarante quer ocultar: - aqui se incluem a embriaguez, a narcose (o famoso "sôro da verdade"), o hipnotismo;

c) os processos que exploram as manifestações involuntárias - fisiológicas ou psicológicas — determinadas no declarante pela emoção: - são os chamados "reveladores da mentira", os "lie-detectors" dos norte-americanos.

A esta última categoria dedicaremos o presente trabalho.

\section{A LINGUAGEM DAS EMOÇõES}

E' bem sabido que a cada fato mental cognitivo (percepção, imagem) corresponde uma repercussão afetiva (emoção), cuja intensidade varia desde a quase indiferença até ao mais profundo abalo do psiquismo. Receber, em dia de aniversário, o presente ambicionado, faz o moço dẹra- 
mar-se de contentamento; saber, no fim do ano, que foi reprovado, leva-o ao abatimento da tristeza ou à exaltação da cólera.

Além da expressão verbal, e mesmo na ausência desta, as emoções têm uma linguagem pela qual se exteriorizam: reações dos músculos em geral, inclusive dos que integram as vísceras (coração, artérias, estômago, intestino, etc.) ; alterações faciais diversas; aumento ou diminuição na atividade glandular (secreção salivar, secreções gastro-intestinais, secreção da bilis, etc.) ; modificações no colorido das faces, no olhar, no tom da voz; aceleração ou demora no ritmo do gesto ou da palavra; etc. Tal conjunto de manifestações, convenientemente interpretado, constitúi aquilo a que usualmente se denomina a "linguagem das emoções"

Admite-se que embora a linguagem das palavras, sujeita à ação da vontade, possa mentir, não o pode a linguagem fisiológica das emoções. Lembrando a frase de TAyllerand, "as palavras foram dadas ao homem para esconder o seu pensamento", adverter KRUKEnBerG": mas a linguagem dos olhos não mente" Por isso, os legisladores antigos, ao mesmo tempo que preveniam contra as declarações verbais, mandavam observar as expressões emotivas. "Que o juiz descubra o que se passa no espírito dos homens, por meio dos sinais exteriores, pelo som da voz, a côr do rosto, a atitude, o estado do corpo, o olhar, os gestos" (1). A arte de interrogar em juizo é, portanto, das mais dificeis. Já o diziam as Ordenações do Reino: "Os enqueredores devem ser bem entendidos, $e$ diligentes em seus Oficios, em modo que saibão perguntar " E recomedavam, quanto à observação das testemunhas: "E atentem bem com que aspecto, e constancia fallão, e se varião, ou vacillão, ou mudão a côr, ou se se torvão na falla, em maneira que lhes pareça que são falsas, ou suspeitas" (2).

(1) Código de Manú, Liv. VHI, n. 25.

(2) Ordenações Filippinas, Liv. I, tit. 86,. Dos Enqueredores. 
Todavia, antes que se oriente em suas decisões pela linguagem emocional, há de o juiz indagar: 1) é suficientemente clara essa linguagem? 2) é digna de confiança?

A "clareza" da Tinguagem das emoções subordina-se, como é óbvio, a duas circumstâncias: à sua universalidade e à sua riqueza em cambiantes expressivas.

Por universalidade entendemos, aqui, o fato de em todos os indivíduos, indistintamente, uma dada emoção se manifestar sempre da mesma forma: sem isso (ou sem a possibilidade de "traduções" disciplinadas), a linguagem não seria inteligível. Pode-se afirmar que as emoções intensas realmente fundamentais, - a cólera, a dôr física, o mêdo, a alegria - possuem um substrato expressivo universal, que permite reconhecê-las no homem como na mulher, no adulto e na criança, no branco e no preto. Mas, quando se trata dessas mesmas emoções em graus reduzidos, ou de outras, mais intelectualizadas, entramos na torre de Babel: sôbre o fundo comum de respostas orgânicas, enxertam-se variantes individuais dependentes do sexo, da raça, da idade, do tipo constitucional, da educação e da cultura, num poliglotismo que a ciência começa apenas a decifrar.

Demais, não seria clara a linguagem que, para exprimir fatos diferentes, empregasse um só e mesmo vocábulo. Possúi o léxico corporal das emoções um vocabulário suficientemente rico para cada tipo e matiz de estados afetivos? Não parece; ou, se possúi, não sabemos lê-lo ainda. Autores vários (Feleky, LANGFeld, etc.) mostraram, por exemplo, que as expresões do ódio e da suspeita são confundidas facilmente com as da cólera, do mêdo, da surpresa.

Nem sempre é clara a linguagem das emoções. E quando clara, será digna de confiança? Em outros termos: não se poderá fazer com ela o que TAyLlerand fazia com as palavras? Por certo que sim, ao menos algumas vezes. Não houvesse essa possibilidade, e a vida social - sem gestos de simpatia simulados, sem a dissimulação de emoções de desagrado - se tornaria extremamente dificil! 
Se, pois, quizermos nos servir, para fins judiciais, da linguagem das emoções, devemos atender aos três seguintes preceitos:

1. escolha, no imenso vocabulário corporal, de expressões emotivas "universais", isto é, que tenham, em idênticas condições objetivas, e qualquer que seja o individuo, a mesma significação;

2. seleção, entre as expressões "universais", das que apresentem significação "específica", isto é, que convenham, sempre e só, a um tipo bem determinado de emoção;

3. verificação apenas das expressões que, independentes da vontade, não possam ser simuladas, nem dissimuladas.

Isto posto, logo se percebe que, embora "bem entendidos", os "enqueredores" das Ordenações não devem fiar-se muito em inferências tiradas dos "sinais exteriores", do "som da voz", da "côr do rosto" E a análise da linguagem das emoções, muito mais dificil que a da linguagem verbal, não pode ser feita no constrangimento de um gabinete policial ou no atropêlo de uma sala de audiência: é trabalho para a calma e a meticulosidade dos laboratórios.

Com essas reservas, passemos a apresentar algumas técnicas que ensáiam descobrir, através das reações emotivas, o segredo do pensamento. Por desejo de abreviar, veremos apenas as seguintes: 1) prova das associações verbais; 2) prova do psicogalvanómetro; 3 ) prova do ritmo respirató. rio; 4) prova da tensão arterial; 5) polígrafos.

\section{A PROVA DAS ASSOCIAÇões VERBAIS}

A pesquiza, em cada individuo, do fenômeno das associações verbais, quer do ponto de vista quantitativo (rapidez das associações, sua riqueza), quer do ponto de vista qualitativo (associações por semelhança, por oposição, por consonância, etc.), tem sido proposta para fins muito diversos: 
para a verificação do gráu de inteligência (GALton), para o diagnóstico de certas anormalidades mentais (Kraepelin, Aschaffenburg, Wahle, Kent, Rosanoff, Murphy), e, especialmente, para a revelação de "complexos" e de perturbações emotivas (Abraham, Jung, Bleuler, etc.). Só trataremos, aqui, deste último aspecto, objetivado pela prova comumente atribuida a Jung e a Bleuler, e cuja base reside em efeitos psicológicos da emoção.

Palavras indutoras. A técnica consiste, essencialmente, em apresentar ao paciente certo número de estímulos verbais ("palavras indutoras"), cada um por vez, e aos quais êle deverá responder pela primeira palavra que lhe venha ao espírito. Se o experimentador disser, por exemplo, "bolso", é possivel que o paciente responda "dinheiro", ou "lenço", ou "roupa"; se disser "jardim", é possivel que responda "flôr", "canteiro", "violeta"; e assim por diante. Um cronómetro, ou, melhor ainda, um cronoscópio permite verificar com exatidão o tempo que vai entre o instante em que o experimentador diz a palavra indutora, e o instante em que o paciente dá a resposta. O registro desse tempo "tempo de reação" - é de fundamental importância.

Não menos importante é a organização prévia da lista de palavras indutoras: deverá haver umas sem qualquer relação com o crime de que o paciente é suspeitado (palavras "indiferentes"), e outras de alguma forma relacionadas com êsse crime (palavras "críticas"). Se, por exemplo, num homicidio para roubo, o autor matou a vítima com uma machadinha, jogou esta numa lagôa, roubou um anel, um relógio, um colar, - as palavras machadinha, lagôa, anel, relógio, colar, serão consideradas "críticas", ao passo que outras, que nada pareçam ter com o crime, tais como mesa, rosa, automóvel, etc., serão "indiferentes"

Os fundamentos da prova. São dois os fundamentos psicológicos capitais da prova: a "vivacidade das associações" e a "perturbação emotiva". 
Um individuo extranho ao crime acima suposto, associará, por exemplo, a palavra "machadinha" com a palavra "lenha" ou "carne", ou "martelo", etc.; ao passo que no espírito do criminoso está muito viva a associação daquela palavra com outras, referentes ao crime, sendo possivel, portanto, que êle dê a resposta "matar", "grito", "lagôa", etc.

Por outro lado, quando o criminoso ouve qualquer palavra que evoque o crime, sobrevem-lhe uma perturbação emotiva, que póde influir sobre a resposta. Ao dizer-se "machadinha" ao inocente, êste responderá naturalmente, sem alterar-se, dando uma associação comum; o criminoso, porem, ou responderá com palavra denunciadora (por causa da viveza da associação); ou então, perturbado, demorará muito na resposta, dará uma resposta extravagante, não dará resposta nenhuma.

Critérios de criminalidade. Efetuada a prova (mediante cuidadosa organização da lista de palavras indutoras, e com o rigoroso registro dos tempos de reação), vai o observador interpretar os resultados obtidos, subordinando-se para isso a seis critérios principais (os três primeiros, quantitativos; os três últimos, qualitativos) :

1. Demora na resposta. O criminoso, ao ouvir o estímulo "machadinha", associar-lhe-á imediatamente "lagôa" ou outra palavra denunciadora; reprime-se, porém, com receio de acusar-se, e escolhe resposta diferente: daí o alongamento do tempo de reação, o qual será, por exemplo, de quatro segundos, em vez de ser de apenas um, como nas respostas suas a estímulos não críticos.

2. Tempo médio de reação. Melhor critério ainda (porque afasta causas de êrro resultantes de "complexos" extranhos ao crime, porventura existentes), consiste em comparar as médias: de um lado, somam-se os tempos de reação das palavras "indiferentes"; de outro, os das palavras "críticas"; a seguir, extráem-se as respectivas médias, que são então confrontadas. Para o inocente, não haverá diferença 
apreciável entre os dois resultados; para o criminoso, a média dos estímulos críticos poderá ser sensivelmente maior.

3. Variabilidade no tempo de reação. Outra observação que se póde fazer é a que se relaciona com o gráu de variabilidade entre os tempos de reação. Para os estímulos indiferentes, embora êsses tempos não sejam rigorosamente iguais entre sí, o desvio entre um e outro (bem como da média dos desvios) não é muito grande; para os estímulos críticos, verifica-se o contrário, desde que o paciente seja o criminoso.

4. Respostas denunciadoras. Pode o criminoso ceder ao impulso de dar, como resposta ao estímulo crítico, a palavra que em seu espírito estava vivamente associada a êle: "machadinha", "lagôa", por exemplo. Entretanto, para que o critério tenha valor, é indispensável que o estímulo seja efetivamente "crítico", e "crítico" por ser o paciente, de fato, o criminoso, e não por outro motivo. Suponha-se que exista. há muito tempo, na memória do paciente, essa associação "machadinha-lagôa", ou então que o paciente tenha lido no jornal a noticia do crime, e se tenha impressionado por êsse pormenor: ficará falseado o resultado.

5. Respostas estéreotipadas. `E' elemento de suspeita, também, o fato de dar o paciente, a muitos estímulos, mórmente aos estímulos críticos, a mesma resposta. Por exemplo: gato, rato; anel, rato; colar, rato. Pode-se supôr que o criminoso, desconfiado, mantém essa palavra de prontidão, para os casos dificeis.

6. Troca de respostas. Quando se repete a experiência, e se pede ao paciente que procure dar, para cada estímulo, a mesma resposta da experiência anterior, o inocente geralmente o faz; o criminoso, não, em relação às palavras críticas.

Resultados. As verificações de laboratório dão, para a prova de Jung-Bleuler, uma alta porcentagem de acertos. Todavia, uma comissão norte-americana (Marston, BurtT e 
Troland), que, durante a grande guerra de 1914-1918, realizou o estudo comparativo dos vários processos de verificação da mentira, depois de aceitar apenas três - o de JuNGBleuler, o de Benussi e o de Marston, - concluio que o das associações verbais é, entre êles, o peor.

Os crimes reais têm, por diversas vezes, prestigiado a prova. O caso original, referido por Jung, deu-se entre estudantes, acusados de haver furtado dinheiro, havendo o furto sido ocultado em uma camisa (só a vítỉma e o experimentador o sabiam). Ao ouvir a palavra "dinheiro" um dos estudantes respondeu "camisa", e com isso se denunciou. Demais, outros elementos foram achados em suas associações, convergindo para o mesmo resultado. Em 1929, Crossland publicou o estudo crítico de sete casos de furtos em repúblicas de estudantes, seis dos quais foram descobertos pela prova de Jung-Bleuler. Em São Paulo, o dr. E. Aguiar WhiTACKER aplicou o processo, no caso do homicidio do "Restaurante Chinês", e admitiu que os seus resultados acusavam o suspeito. $\mathrm{O}$ dr. A. Teixeira Lima comunicou-me também um caso seu, particular, coroado de êxito.

Na opinião de Burtr, que a experimentou detidamente, a prova de Jung-Bleuler não deve ser despresada; mas, além da precaução de acompanhar-se sempre de outras, precisa ser efetuada com prudência e interpretada com reservas (3).

\section{O REFLEXO PSICOGALVÂNICO}

O Sacro Império Romano (comenta Ruckмıск) não era nem sacro, nem Império, nem Romano: também o reflexo psicogalvânico (acrecenta) não é necessariamente psíquico, nem galvânico, nem reflexo. Sua história, à qual se prendem os nomes de Charles Féré (1888), Tarchanoff (1888), E. K. Muller (1904), Veraguth (1906), Jung, Bleuler, etc.,

(3) Burtt (H. E.) - Legal Psychology, N. York, 1931. 
teve antes de si uma pre-história, de observação empírica. Sabiam os Indús que as emoções de mêdo - e entre elas a que o criminoso experimenta no ato de mentir - reduzem a secreção salivar, deixando a bôca sêca: o acusado que não pudesse mastigar e cuspir o arroz estaria mentindo.

Conhecia-se, por outro lado, o estímulo que as emoções determinam na secreção de suor. Shakespeare assinala em uma de suas peças (Véspera de Reis) a secura das mãos dos namorados, quando dizem palavras de amor fingidas.

Por sucessivas experiências, verificaram os cientistas que quaisquer emoções estimulam subitamente a sudorése, e que, portanto, notar, em determinado individuo, as alternativas de intensidade desse fenômeno, equivale a surpreender as suas emoções.

Como registrar, porém, as delicảdas variações na atividade das glândulas sudoríparas? De forma muito simples: pelas alteraçõ̃es que o corpo do individuo apresente, na resistência à passagem da corrente elétrica.

O psicogalvanómetro consta, essencialmente, de uma bateria de pilhas, às quais se anexa um galvanómetro (destinado a medir as variações da corrente). O polo positivo da bateria é ligado ao polo negativo por um fio metálico: êste fio, entretanto, é interrompido, afim de intercalar-se no circuito o corpo do paciente. Para isso, o paciente segurará, com cada mão, uma das extremidade do fio: mais precisamente, colocará as mãos abertas sôbre duas placas de cobre, cada uma ligada a um dos segmentos do fio. Estando as mãos sêcas, o contacto não será íntimo, a passagem da corrente se fará dificilmente; estando úmidas, dar-se-á o contrário, - sendo tudo isso registrado pelo galvanómetro.

Faça-se ao paciente uma pergunta indiferente: não haverá aumento na sudação das mãos, nenhum acréscimo na corrente elétrica será acusado pelo aparelho. Pergunte-selhe, porem, qualquer coisa que o emocione: imediatamente o galvanómetro revelará corrente mais intensa.

Os autores que têm trabalhado com o psicogalvanómetro consideram-no um excelente registrador de emoções. 
Dentre essas, as que mais se acusam pelo aparelho são as de mêdo. Também a emoção causada pelo ato de mentir é nele assinalada (4).

Nas experiências de laboratório, em que é possivel reduzir todas as emoções do paciente unicamente às da mentira, o psicogalvanómetro dá bons resultados. Nos casos reais, porem, êle acusa muito mais o mêdo que a mentira - mêdo do aparelho, mêdo da experiência, mêdo de se estar denunciando - de sorte que seus dados serão de interpretação dificílima (Marston).

\section{A PROVA Do RITMO RESPIRATórIO (BENUSSI)}

Toda gente conhece a influência que as emoções determinam sôbre o ato respiratório; a dificuldade, porém, está em relacionar cada tipo de alteração com um tipo específico de emoções. No particular que nos interessa, será preciso descobrir a influência precisa exercida sôbre a respiração, pela emoção de mentir. Foi o que Benussı julgou encontrar, desde 1914.

O essencial do processo consiste em registrar, para cada ato respiratório, a duração discriminada da inspiração (I) e da expiração (E), podendo-se assim calcular o "quociente $1 \mid \mathrm{E}$ ". Emprega-se, para êsse efeito, um "pneumatógrafo"

Propõe-se uma pergunta ao paciente, pedindo-se-lhe que aguarde, para responder, um determinado sinal, que será dado depois de poucos segundos. Enquanto espera para responder, o paciente prepara-se, ou para falar a verdade, ou para mentir: conforme o caso, a influência sobre o ritmo respiratório variará.

(4) Num caso pericial, empregamos uma vez um psicogalvanómetro simplificado, do laboratório do dr. J. PENnino, com o fim de verificar o grau de emoção da paciente perante certos estímulos verbais: os resultados coincidiram com os de outras provas, que mostraram a reduzida repercussão afetiva dos estimulos, na moça examinada. 
E' preciso, a cada pergunta, registrar o valor de I (inspiração) e de $\mathrm{E}$ (expiração), antes e depois da resposta do paciente; bem como calcular o quociente de I|E dos atos correspondentes aos dois periodos. Assegura Benussi, baseado em suas experiências, que: 1) se o valor médio de $I \mid E$ antes da resposta, é maior do que o valor médio desse quociente, depois da resposta, o individuo está dizendo a verdade; 2) se o valor de $\mathrm{I} \mid \mathrm{E}$, antes da resposta, é menor do que depois, o individuo está mentindo.

As experiências de laboratório não invalidam de todo a prova de Benussi, mas também não a prestigiam suficientemente: as diferenças no valor médio de $I \mid E$ ou não existem, ou são pouco pronunciadas, o que, aliás, facilmente se explica, pois no laboratório é impossivel conseguir situações de intensidade emotiva comparável às dos crimes reais. Numa experiência constituida de 11 casos artificiais, o diagnóstico pela prova respiratória foi exato em 8 , ao passo que a prova de Marston acertou 10 vezes.

Numa série de 6 acusados, submetidos à experiência por KLEMm, pôde êste autor notar que os resultados se mostram tanto menos pronunciados quanto mais antigo o fato a respeito do qual o individuo mente; donde mais um argumento em favor do interrogatório precoce dos criminosos.

A prova de Benussi está sendo usada na policia norteamericana, como elemento subsidiário na revelação da mentira.

\section{A PRova da tensão arterial (Marston)}

Dos diferentes processos científicos empregados como "reveladores da mentira", o que, até hoje, parece ter obtido melhor êxito, é a prova da tensão arterial, ou "prova de MARSTON".

Histórico e teoria. Recorramos ao que diz o próprio Marston (5). Em 1915, efetuara êle diversas tentativas afim de disciplinar a prova de Jung-Bleuler, mas em vão: os

(5) Marsion (W. M.) - The Lie Detector Test, N. York, 1938. 
resultados se mostravam inseguros ou contraditórios. Uma hipótese surgiu-lhe, então, no espírito. O homem, quando mente, realiza um esforço voluntário suplementar, que obriga o coraçã் a bater com energia maior, e, portanto, a pressão sanguínea a subir. Nesse tempo, uma moça de outro laboratório, interessada em pesquizas sobre fenômenos de psicologia, escrevia a MARston dizendo-lhe que quando as pacientes dela mentiam, o pulso lhes batia mais forte. Com a colaboração dessa moça ("que depois, diz êle, se tornou minha companheira tanto no laboratório como na vida doméstica”) pôde Marston estudar e propôr a sua prova.

Para registrar o fenômeno, basta um aparelho comum, igual ao que usam os cardiologistas quando investigam a pressão sanguínea de seus doentes: um esfigmomanómetro "Tycos", por exemplo (Marston se defende reiteradamente da imputação de haver "inventado um aparelho" revelador da mentira. ). Pode-se empregar tambem (como faz JARson) um dispositivo que inscreva o registro contínuo das variações da pressão.

Dir-se-á : mas ao vir sofrer a prova, já o individuo está emocionado, e por isso sua pressão se eleva. Sim, responde Marston, mas além do acréscimo geral da emoção, haverá, em cada mentira, o acréscimo peculiar a esta. MArston acredita, em suma, que o ato de mentir tem, sobre a tensão arterial, uma eficácia maior que a de qualquer emoção; e nisso está, ao que parece, o ponto fraco da teoria.

Originariamente, eram feitas ao paciente perguntas que exigiam respostas mais ou menos longas, o que dificultava a experiência e nela introduzia causas de êrro. Larson simplificou a técnica, organizando, para cada caso, perguntas que se respondam unicamente por "sim" ou "não".

Experiências de laboratório. As experiências originais de Marston consistiram em "crimes de laboratoório" Efetuados êstes, foram acusados 107 estudantes, alguns dos quais "criminosos" e outros "inocentes" Um juri julgou a 
todos; e, ao mesmo tempo, todos passaram pela prova da tensão arterial. 0 juri falhou 54 vezes; a prova falhou 4 . Das quatro falhas da prova (explica o autor), três se deram porque estudantes "inocentes" enxertaram, propositadamente, mentiras em suas declarações; uma, porque o aparelho fôra mal colocado.

Em 1929, Chappell efetuou também pesquizas de laboratório sobre a prova: num total de 40 pacientes, houve $87 \%$ de resultados certos. Em 10 "crimes" artificiais investigados por Marston, Burtt e Troland, a proporção de acertos foi de $100 \%$.

A prova de Marston e a espionagem. Marston, Burti e Troland foram encarregados pelas autoridades norte-americanas, em 1917, de apontar os melhores processos para a inquirição e descoberta dos espiões. Num estudo preliminar, achou a comissão que só convinha reter três provas: a de Marston, a de Benussi e a de Jung-Bleuler. Experimentadas as três em numerosos casos artificiais ou reais, concluio a comissão atribuindo os seguintes valores à fidelidade de cada uma delas: prova de Marston, $97 \%$; prova de Benussi, $73 \%$; prova de Jung-Bleuler, pouco mais de $50 \%$, isto é, pouco mais que o acaso.

Houve um caso real interessante. Certo código secreto desaparecera de um hospital militar em que trabalhavam 70 mensageiros negros. Qual destes seria o responsável? Resolveu-se aplicar a prova da tensão arterial. Os negros estavam aterrorizados, diversos tiveram que ser levados à força ao gabinete. A prova demonstrou que quáse todos haviam furtado alguma coisa - pacotes de lápis, escovas, peças de vestuário, instrumento cirúrgicos. Ficou também claramente identificado o ladrão do código, e o código foi recuperado.

A prova de Marston na policia. Larson (que, depois de diplomado em medicina, iniciou sua carreira policial, como polícia comum), tem empregado largamente a prova de MaRston, aperfeiçoando-a. 
Os jornais norte-americanos referem (provavelmente com exagero. ) a anedota da estréa. Num dormitório feminino da Universidade da Califórnia, em 1921, começaram a desaparecer, cada noite, objetos, peças de vestuário, joias. Os "detectives", chamados a esclarecer o mistério, não o conseguiram. Entregaram o caso a Larson, que acabava de regressar de suas férias. Resolveu o jovem polícia ensaiar a prova de MARSton, cuja descrição lêra em um jornal científico. Chamou a exame, pois, a primeira queixosa, encontrando, nos seus resultados, uma curva de perfeita sinceridade. Chamou outra, mais outra, etc., até que uma das moças foi denunciada pela prova. A moça, aliás, confessou e restituio os objetos. Quiz Larson, então, submeter a exame, de novo, a primeira queixosa, que êle logo de inicio achara "tão sincera quanto bonita" E perguntou-lhe: "Você quer casar comigo ?" A moça respondeu vivamente: "Não!” Mas o aparelho registrou aí a sua primeira mentira. $O$ fato é que estão casados.

Hoje, mais de cem repartições policiais norte-americanas usam a prova de Marston.

A prova de Marston e os tribunais. A propósito do assassinio do médico negro dr. Brown, a prova de Marston, aplicada no acusado Jim Frey, mostrou que êste era inocente. Todavia, o tribunal recusou-a: "Pensamos (disseram os juizes) que a prova da mentira, baseada na pressão sístólica do sangue, ainda não alcançou suficiente crédito da parte das autoridades em fisiologia e psicologia, para que se possa aceitar um parecer pericial com fundamento em verificações e experiências feitas com ela" Isto se deu em 1923. Posteriormente, o verdadeiro assassino do dr. Brown apareceu, mostrando que a prova não enganara.

Um caso curioso ë referido por Burtr. Certa vez, durante um processo por furto, um amigo da familia lesada compareceu ao tribunal, para depôr; sugeriu-se então que o submetessem à prova de MARSTon. Quando lhe perguntaram, a título de curiosidade "Foi você que furtou o dinhei- 
ro?", êle respondeu "Não!"; mas o aparelho mostrou que a resposta era mentirosa. De fato o gatuno era êle.

Até agora, a prova de MARston foi admitida por quatro Estados norte-americanos, em seus tribunais. Deve ela, porem, no parecer de BurTt e no do próprio MARston, manter-se sempre como prova propriamente "pericial", efetuada e interpretada na serenidade dos gabinetes, e nunca uma prova pública, para ser realizada perante o júri. Ainda mais: não deverá sair do dominio médico especializado.

Conta Marston os esforços que fez para submeter à sua prova o célebre Hauptmann, executado como assassino do pequeno Lindbergh: não lh'o permitiram, entretanto, as formalidades processuais, a despeito do interêsse manifestado pelo governador Hoffman, de Nova Jersey.

A prova de Marston nas casas comerciais Mais de $\mathbf{5 0}$ estabelecimentos bancários adotam a prova de Marston, segundo informa o seu autor em 1938. Alguns o fazem em relação aos candidatos à primeira nomeação. Outros (e é tendência geral) a praticam periodicamente, afim de verificar se seus funcionários não estão, porventura, em situação financeira embaraçosa, ou planejando algum desfalque.

A diretoria de uma grande companhia (conta Marston) quiz introduzir a prova nos seus escritórios. Um dos altos funcionários fez grande oposição, com argumentos de colorido científico: mas a maioria se mostrou favorável à experiência; todos passaram por ela, inclusive o presidente. Quando chegou a vez do opositor, descobriu-se que êle tramava um desfalque, - o que, aliás, ficou depois plenamente demonstrado.

A prova de Marston na vida íntima. o campo de ação de qualquer "revelador de mentira" é tão grande como o da própria mentira, o que vale dizer que tal aparelho encontrará aplicação em todas as relações sociais. Conta o prof. Afrânio Peixoto que, viajando pelos Estados Unidos, quiz ir, com o prof. Negrão de Lima, assistir a uma demonstração do "lie detector". Serviu de paciente o próprio prof. 
Negrão de Lima, a quem o experimentador recomendou que respondesse sempre "não". - "Vou dizer a sua idade (declarou êste)": 35 anos?” "- Não!" "- 36 ?" "— Não!” "- 37 ?" “- Não!” E assim sucesivamente, até 40 e poucos anos. “- O senhor tem 38 anos!" exclamou o experimentador. De fato, ao responder "Não!" para essa idade, o prof. NEGRÃo dE LIMa não havia sido inteiramente verídico...

Um consultório de psicologia, de Marston, tem resolvido, graças à sua prova, diversos casos íntimos, cujo ponto de partida era uma desconfiança infundada.

\section{POLfGRAFOS. CONCLUSõES}

Conquanto promissora de êxito, a prova de Marston (afirmam-no Burtt, Larson, Keeler, etc.), não merece ainda a paternal confiança que nela deposita o seu descobridor. Investigações mais extensas e mais variadas precisam ser efetuadas, para que se possa afastar ou reconhecer o efeito de fatores extranhos, que falseiam os resultados.

Por enquanto, qualquer das provas mencionadas deve ser fiscalizada pelas outras - dispondo-se, quanto ao mérito, na seguinte ordem: 1) prova de Marston; 2) prova de Benussi; 3) prova de Luria (baseada nas alterações nêuromusculares); 4) prova de Jung-Bleuler; 5) prova do psicogalvanómetro. Daí os "polígrafos", que inscrevem contemporaneamente várias reações. LARSON e seus colaboradores aconselham o "fotopolígrafo" fabricado sob o influxo das investigações de Darrow, e que consigna a curva da tensão arterial, a do ritmo respiratório, a de Luria e a do psicogalvanómetro.

Isoladas ou mesmo associadas, estas provas se acham, no momento, em trânsito do laboratório experimental para a policia e os tribunais. Funcionam por ora, de preferência, junto à policia. Até 1932, LARSon e Keeler haviam examinado com elas cerca de 10.000 casos, errando apenas 
em dez (6). Da sagacidade destes dois investigadores, não se pode duvidar. Inúmeros outros, porém (quem os denuncia é uma revista médica norte-americana), usam os aparelhos sem entender os principios psicológicos que os fundamentam, e, operando mecanicamente, transformam uma prova científica em verdadeiro processo de tortura mental (7). Inútil acrescentar que a propaganda dos fabricantes de polígrafos está contribuindo, por sua vez, para a vulgarização do método em mão incompetentes.

Por tudo isso e também pela imaturidade das provas, LARSON e seus auxiliares (o que é muito significativo) se opõem a que os "reveladores da mentira" consigam desde já ingresso na prática forense: não possuem ainda, em seu parecer, o suficiente grau de precisão que o uso judiciário exige. Fiquem por enquanto só na policia, como instrumentos de seleção de suspeitos, na fase preliminar das investigações (8).

Entretanto, diversos tribunais norte-americanos têm recebido laudos periciais baseados na linguagem das emoções. Ainda em principios de 1939, a côrte estadual de Nova York deu como "indiscutíveis" as deduções, extraidas por peritos, dos resultados fornecidos por um psicogalvanómetro.

Se feitas com segurança e interpretadas com prudência, nada impede, de fato, que os tribunais aceitem as investigações efetuadas por intermédio dos "tests" da emoção: aceitem-nas, porém, ao menos por enquanto, como simples subsídio, e não como prova por si mesma decisiva.

(6) Ruckmick - The Psychology of Feeling and Emotion, N. York, 1936, pag. 309. Esses dados, extraidos de um trabalho de KeEler (How science solves crime, Hygeia, 10, 1932), conferem, se exatos, enorme valor à prova poligráfica.

(7) Journal of the Amer. Med. Ass. - Editor, 28 jan. 1939.

(8) Larson, Canty E Broom - La Verdad acerca del Indicador de Mentiras, Arch. Chilenos de Criminologia, Tomo I, dez. 1937. 